Projeto de gestão integrada da orla marítima. A experiência do município de Campos dos Goytacazes, Rio de Janeiro, Brasil.

Eduardo Manuel Rosa Bulhoes, Stéphanie Katrin Vianna Klotz, Izaura da Silva Arêas Mota, Tatiane Cardoso Tavares, Juliana Bastos Sanguêdo, Carolina Almeida Santos Cidade

\title{
PROJETO DE GESTÃO INTEGRADA DA ORLA MARÍTIMA. A EXPERIÊNCIA DO MUNICÍPIO DE CAMPOS DOS GOYTACAZES, RIO DE JANEIRO, BRASIL
}

\section{Integrated management project of maritime orla. The experience of Campos dos Goytacazes munici- pality, Rio de Janeiro, Brazil.}

Eduardo Manuel Rosa Bulhoes Universidade Federal Fluminense, Campos dos Goytacazes, Rio de Janeiro, Brasil. eduardobulhoes@id.uff.br

Stéphanie Katrin Vianna Klotz Universidade Federal Fluminense, Campos dos Goytacazes, Rio de Janeiro, Brasil. stephanieklotz@globomail.com

Izaura da Silva Arêas Mota Secretaria Municipal de Meio Ambiente, Campos dos Goytacazes, Rio de Janeiro, Brasil. izaura.areas@gmail.com

Tatiane Cardoso Tavares Secretaria Municipal de Meio Ambiente, Campos dos Goytacazes, Rio de Janeiro, Brasil. tatianecardoso@live.com

Juliana Bastos Sanguêdo Secretaria Municipal de Meio Ambiente, Campos dos Goytacazes, Rio de Janeiro, Brasil. julianasanguedo@gmail.com

Carolina Almeida Santos Cidade Universidade Federal Fluminense, Campos dos Goytacazes, Rio de Janeiro, Brasil. julianasanguedo@gmail.com

Artigo recebido em 11/08/2015 e aceito para publicação em 15/07/2016

RESUMO: Em Campos dos Goytacazes-RJ, o Projeto Orla vem sendo articulado envolvendo as três esferas de poder e a representação da sociedade civil. Iniciou em dezembro de 2009 objetivando promover a gestão sustentável da orla e assegurar a preservação ambiental e o ordenamento da orla denominada Farol de São Thomé. O objetivo geral do artigo é registrar o processo de implantação do projeto, expondo etapas cumpridas, participação dos atores, questões de interesse e resultados alcançados. A municipalidade é responsável pela adesão e, com a sociedade civil, pela ação mais direta do projeto. Atuam nas etapas de diagnóstico, subdivisão em unidades de paisagens e trechos, levantamentos de usos, identificação de problemas e elaboração de cenários desejados. Os conflitos pelo uso das áreas naturais esbarram nas atividades já consolidadas e identificadas como geradoras de problemas como o comércio, a pesca, turismo e construção civil. O PGI (Plano de Gestão Integrada) foi consolidado e submetido à avaliação da 
Projeto de gestão integrada da orla marítima. A experiência do município de Campos dos Goytacazes, Rio de Janeiro, Brasil. Eduardo Manuel Rosa Bulhoes, Stéphanie Katrin Vianna Klotz, Izaura da Silva Arêas Mota, Tatiane Cardoso Tavares, Juliana Bastos Sanguêdo, Carolina Almeida Santos Cidade

instrutora do Projeto Orla que, em março de 2014, atestou sua adequação à metodologia específica. Em seguida, foi encaminhado às coordenações técnica nacional e estadual que emitiram parecer favorável com suas considerações, recomendações e sugestões de adequação, em dezembro de 2014. O PGI e o Comitê Gestor foram finalmente homologados em audiência pública no dia 16 de maio de 2015. Destaca-se que foi a primeira homologação no estado do Rio de Janeiro. No momento atual ocorrem as reuniões iniciais do Comitê Gestor e as pautas que visam consolidar as ações programadas para a orla do município.

Palavras-chave: Projeto Orla; Gerenciamento Costeiro; Plano de Gestão Integrada; Campos dos Goytacazes.

ABSTRACT: In Campos dos Goytacazes municipality, the articulation of Orla Project involves the three branches of power and the representation of civil society. It started in December 2009 aiming to promote the sustainable management of the waterfront and ensure environmental preservation and coastal planning. The overall objective of this paper is to register the project implementation process, exposing met steps, stakeholder participation, issues of interest and results. The municipality is responsible for membership, and with civil society, by the most direct action in project. They work in diagnostic steps, subdivision into landscape units and stretches, uses surveys, problem identification and preparation of desired scenarios. The conflicts over the use of natural areas come up against the already established activities and identified as generating issues such as trade, fisheries, tourism and civil construction. The PGI (Integrated Management Plan) was consolidated and submitted to the assessment of instructor of the Orla Project, in March 2014, who attested its adaptation to the specific methodology. Then it was sent to national and state technical coordination, which issued a favourable opinion with his remarks, recommendations and suggestions adequacy in December 2014. The PGI and the Steering Committee were finally approved in open court on 16 May 2015. It is noteworthy that it was the first approval in the state of Rio de Janeiro. Now occur the initial meetings of the Steering Committee and the guidelines that aim to consolidate the actions scheduled for the council's edge.

Keywords: Coastal Management; Coastal Zoning; Campos dos Goytacazes; Integrated Management Plan

\section{INTRODUÇÃO}

O Plano Nacional de Gerenciamento Costeiro (PNGC) instituído pela Lei Federal 7.661/88 faz parte da Política Nacional para os Recursos do Mar (PNRM) e da Política Nacional do Meio Ambiente (PNMA). O Projeto de Gestão Integrada da Orla Marítima (Projeto Orla) surge neste contexto como uma iniciativa do Governo Federal, conduzida por ação conjunta entre o Ministério do Meio Ambiente (MMA), por meio da Secretaria de Qualidade Ambiental (SQA) nos Assentamentos Humanos, e pela Secretaria do Patrimônio da União (SPU) do Ministério do Planejamento, Orçamento e Gestão (MPOG). Suas ações buscam o ordenamento dos espaços litorâneos sob domínio da União, com os objetivos de promover a descentralização da gestão da orla marítima, fortalecer a articulação de diferentes atores e compatibilizar as políticas ambiental e patrimonial do governo federal com as políticas locais, orientando a sociedade a utilizar de maneira racional os recursos da zona costeira (MMA, 2006a).

A adesão ao Projeto Orla é um ato voluntário e deve ser formalizada de modo a manifestar o interesse direto do executivo municipal assim como o compromisso com o desenvolvimento das fases de implantação. Por sua vez, essas ocorrem a partir da seleção das localidades a serem inseridas no processo, com oficinas, reuniões e disponibilização de dados e informações necessárias para que se elabore um dossiê sobre as áreas de interesse. Por fim, é feita uma análise final do principal produto que é o PGI - Plano de Gestão Integrada, emitindo um parecer técnico em conjunto com a Coordenação Estadual e só então é possível a implantação dos planos de gestão, viabilizando os meios disponíveis e potenciais, em sua esfera de ação, para apoiar a execução das ações propostas (MMA, 2006b). 
Projeto de gestão integrada da orla marítima. A experiência do município de Campos dos Goytacazes, Rio de Janeiro, Brasil.

Eduardo Manuel Rosa Bulhoes, Stéphanie Katrin Vianna Klotz, Izaura da Silva Arêas Mota, Tatiane Cardoso Tavares, Juliana Bastos

Sanguêdo, Carolina Almeida Santos Cidade

\section{ESTUDO DE CASO: CAMPOS DOS GOYTA- CAZES/RJ}

No município de Campos dos Goytacazes (RJ), o Projeto Orla vem sendo implementado e articulado de forma participativa envolvendo as três esferas de poder e a representação da sociedade civil. Estas entidades são a Secretaria de Patrimônio da União (SPU), a Superintendência de Patrimônio da União no Rio de Janeiro (SPU-RJ), o Instituto Estadual do Ambiente (INEA), a Secretaria Municipal de Meio Ambiente (SMMA), as representações das associações locais de moradores (Associação de Moradores e Amigos do Farol de São Thomé (AMAFROL); Associação de Moradores do Xexé), Associação de Hotéis, Pousadas, Comércio e Similares da Praia do Farol de São Thomé (ASCHCOM), Colônia de Pescadores (Z-19), Universidade Federal Fluminense (UFF), Universidade Federal Rural do Rio de Janeiro (UFRRJ), Projeto TAMAR (ICMBio - Base Bacia de Campos), além da Secretaria Municipal de Obras e Urbanismo, Secretaria Municipal de Agricultura e Pesca, Secretaria de Turismo, Guarda Civil Municipal, Superintendência de Postura e o Centro de Informações e Dados de Campos (CIDAC).

O processo teve início em dezembro de 2009 com o intuito de promover uma gestão sustentável da orla marítima, além de desenvolver e programar gradativamente ações para assegurar a preservação ambiental e o ordenamento de utilização da faixa litorânea, considerando sua extensão ininterrupta de praia $(28 \mathrm{~km})$, denominada Farol de São Thomé. Em termos administrativos, a orla do município é atualmente subdividida entre o $3^{\circ}$ Distrito - Santo Amaro e o $5^{\circ}$ Distrito - Mussurepe. Apesar de ser uma praia arenosa ininterrupta, coexistem características ambientais distintas como áreas bem preservadas de restinga e de mangue, lagoas e lagunas, assim como características de ocupação distintas como áreas urbanizadas, áreas em processo de urbanização e áreas desocupadas.

\section{OBJETIVOS}

O objetivo geral do presente artigo é registrar e divulgar o processo de implantação do Projeto Orla no município de Campos dos Goytacazes, expondo as etapas cumpridas, a participação dos atores envolvidos, as principais questões de interesse e os principais resultados alcançados.

O objetivo específico é, no contexto do Projeto Orla do município, apresentar as ações tomadas para definir orientações para o uso adequado e o ordenamento da orla, compatibilizando as políticas ambiental e patrimonial de forma a reduzir os impactos da ocupação e do uso da orla marítima.

\section{ÁREA DE ESTUDO \\ Aspectos Ambientais}

A zona costeira do município de Campos dos Goytacazes (Figura 1) está inserida no macro compartimento da Bacia de Campos, no Litoral Oriental (ou leste) brasileiro de acordo com o proposto por Muehe (1998). 
Projeto de gestão integrada da orla marítima. A experiência do município de Campos dos Goytacazes, Rio de Janeiro, Brasil. Eduardo Manuel Rosa Bulhoes, Stéphanie Katrin Vianna Klotz, Izaura da Silva Arêas Mota, Tatiane Cardoso Tavares, Juliana Bastos Sanguêdo, Carolina Almeida Santos Cidade

Figura 1 - Mapa de Localização da Área de Estudo, Unidades de Paisagem e Limites Continental e Marinho do Projeto Orla em Campos dos Goytacazes.

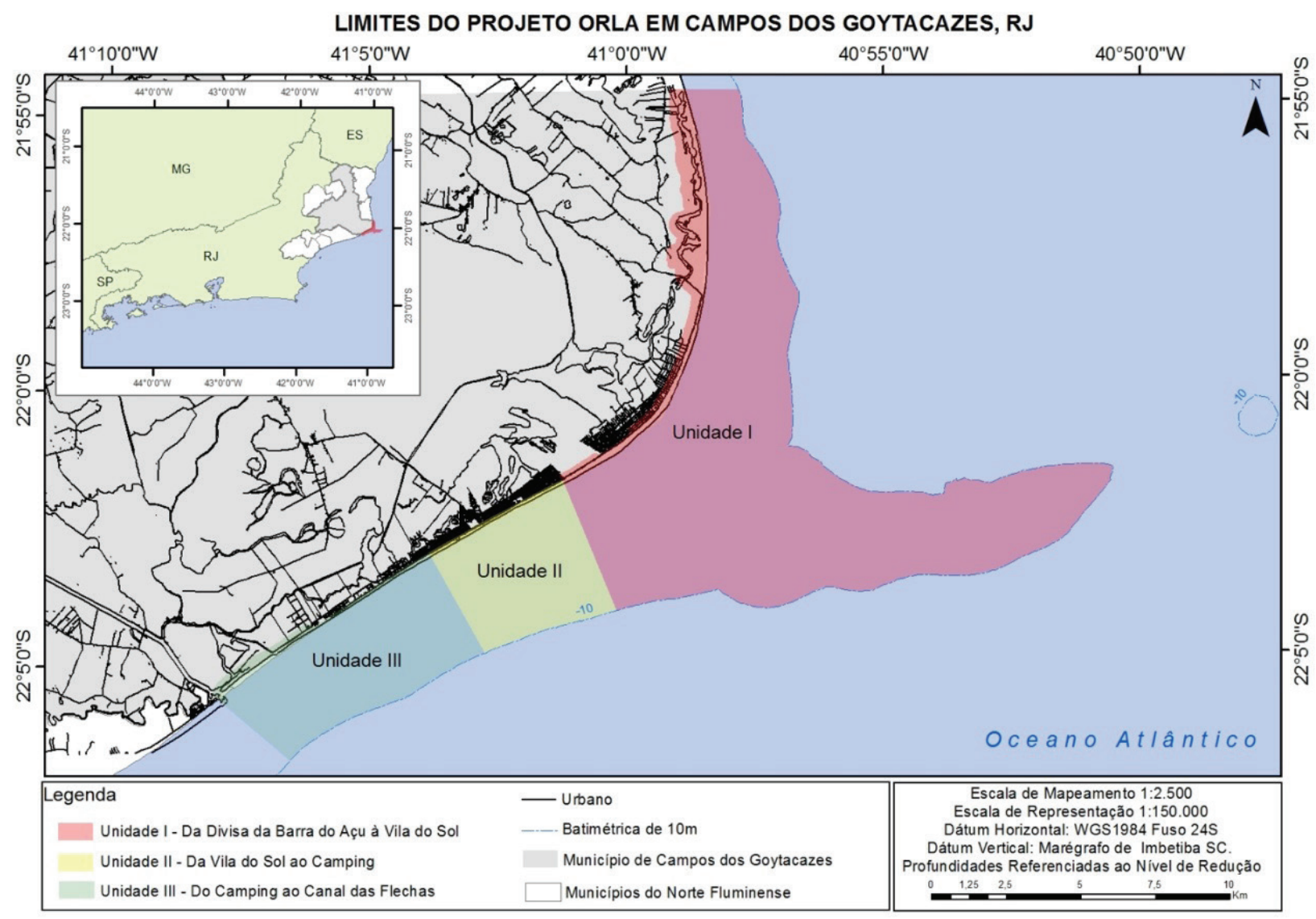

Org. os autores.

O que se destaca neste compartimento do litoral fluminense é a planície costeira aonde se desenvolve o delta do rio Paraíba do Sul, uma feição sedimentar protuberante mar adentro, que tem sua história geológica entendida a partir das duas últimas grandes transgressões, e posteriores regressões, do nível do mar e também associada aos depósitos fluviais ao longo do quaternário tardio. A partir do cabo de São Thomé em direção ao sul as barreiras arenosas da borda oceânica estão expostas a processos de transposição de ondas (overwash) promovendo a migração desta feição em direção ao continente. Por outro lado, ao norte do cabo de São Thomé, as barreiras arenosas apresentam características regressivas (cristas de praia), já diretamente influenciadas pela atual sedimentação do rio Paraíba do Sul e evoluem em direção ao oceano. Assim, o cabo de São Thomé marca uma posição limítrofe de características geomorfológicas distintas, que se refletem também em condições de transporte litorâneo convergente (CASSAR; NEVES, 1993) e marca a inflexão desta porção do litoral. A porção ao sul do cabo volta-se para sudeste e a porção ao norte volta-se para nordeste, o que é significativo em termos de exposição às ondas de tempestade, transporte de sedimentos e características dinâmicas das praias.

As características sedimentares encontram-se sob influência da sedimentação fluvial atual (neotérica) promovida pelo rio Paraíba do Sul que deposita sedimentos junto ao oceano e neste, sobretudo pelo predomínio dos ventos do quadrante nordeste e das ondas geradas, promove o transporte das areias majoritariamente para sul, sendo estas as fontes das areias médias e grossas que recobrem a faixa costeira do município e as lamas (siltes e argilas) que recobrem 
Projeto de gestão integrada da orla marítima. A experiência do município de Campos dos Goytacazes, Rio de Janeiro, Brasil.

Eduardo Manuel Rosa Bulhoes, Stéphanie Katrin Vianna Klotz, Izaura da Silva Arêas Mota, Tatiane Cardoso Tavares, Juliana Bastos

Sanguêdo, Carolina Almeida Santos Cidade

a porção submarina adjacente (MUEHE, 2006). Adicionalmente, há inversão do transporte litorâneo na porção sul do litoral do município, por ocorrência de ondas fortes do quadrante sul e sudeste que acabam por convergir os fluxos para norte (CASSAR; NEVES, 1993), em direção à zona mais protuberante do litoral.

Levantamentos recentes indicam que a largura média dos $28 \mathrm{~km}$ de praia na orla do município é de 145 metros com um padrão tendendo a mais largo nas extremidades do arco praial e mais estreito na porção central. Já a altura média da barreira arenosa frontal é de 4,0 metros acima do nível médio do mar, com a tendência de ocorrerem dunas frontais baixas em direção à porção norte da linha de costa.

Sob o ponto de vista morfodinâmico, a faixa costeira em questão é exposta diretamente às ondas oceânicas, e composta por areias siliciclásticas de granulometria média e grossas e perfis de praia que variam entre o refletivo (ao sul) e intermediário (ao norte). Tal mudança nas características morfodinâmicas ao longo da linha de costa ocorre em função da mudança na orientação da linha de costa e consequentemente no padrão de incidência das ondas.

Quanto às características meteoceanográficas predominam ventos do quadrante nordeste, com intensidades entre 4,0 e $8,0 \mathrm{~m} / \mathrm{s}$ que não raro atingem picos acima de $12 \mathrm{~m} / \mathrm{s}$. As ondulações incidem com maior frequência das direções su-sudeste e de lestenordeste. As ondas de sul e sudeste podem chegar com alturas significativas de $3,0 \mathrm{~m}$, porém os padrões mais frequentes são de ondas entre 1,0 e 2,0 metros (PINHO, 2003). Já para ondas de Leste Nordeste a maior frequência de alturas é com valores entre 0,5 e 1,0 metro.

\section{Limites do Projeto Orla em Campos dos Goytacazes}

A orla marítima pode ser definida como unidade geográfica delimitada pelo contato entre a terra firme e o mar. A tipologia de feições na faixa costeira da área de estudo são as praias arenosas e os manguezais. Tipologias diferentes de feições possibilitam usos diferentes e diferentes são as necessidades de intervenção. As praias arenosas são as áreas prioritárias de regulamentação e ordenamento já que recebem maior adensamento de uso por parte da população e por ações da administração municipal.
Os limites estabelecidos pelo Projeto Orla incorporam um limite marinho e um limite continental. A definição desses limites (MMA, 2006a) é feita a partir da linha de preamar máxima (LPM) ou do limite final de ecossistemas tais como os caracterizados por feições de praias, dunas, áreas de escarpa, falésias, costões rochosos e etc. O limite marinho é a isóbata de 10 metros delimitada através de rotinas de digitalização e interpolação de dados de Cartas Náuticas (ex. CN1403) disponibilizadas pela Marinha do Brasil. O limite continental ocorre no contato entre a terra e o mar (neste caso na praia) e a partir deste são definidos uma faixa de 50 metros para áreas urbanizadas e 200 metros para áreas não urbanizadas, delineados na Figura 01.

Neste trabalho, o limite continental foi projetado no contato entre as areias de praia e a retroterra, onde foi detectada alguma mudança da vegetação ou do ambiente geomorfológico. Adicionalmente, nos locais aonde ocorrem dunas frontais, o reverso destas foi utilizado como a linha de delimitação. No caso das áreas de mangue os limites foram determinados a partir das margens voltadas para o continente.

\section{METODOLOGIA DE EXECUÇÃO DO PROJE- TO ORLA NO MUNICÍPIO}

As etapas anteriores às atividades concentradas no município são a geração de insumos e mobilização pelo MMA e pela SPU. Em seguida, a articulação destes órgãos com os governos estaduais e municipais visam sensibilizar, instrumentalizar e garantir o apoio dos respectivos órgãos ambientais a aderir e implementar o Projeto Orla no município, sendo este o responsável pela adesão e, aliado a uma ação efetiva da sociedade civil organizada, atuam de forma direta na implementação do projeto.

A partir da definição da coordenação municipal foi realizada como atividade inicial a $1^{\mathrm{a}}$ Oficina (julho de 2010). Reuniu-se a coordenação federal, estadual e municipal que obtiveram a adesão da sociedade civil organizada (duas associações de moradores, duas universidades federais, projeto TAMAR, colônia de pescadores, associação comercial) dentre outros representantes governamentais e não governamentais supracitados. As oficinas são trabalhos que servem 
Projeto de gestão integrada da orla marítima. A experiência do município de Campos dos Goytacazes, Rio de Janeiro, Brasil. Eduardo Manuel Rosa Bulhoes, Stéphanie Katrin Vianna Klotz, Izaura da Silva Arêas Mota, Tatiane Cardoso Tavares, Juliana Bastos Sanguêdo, Carolina Almeida Santos Cidade

para orientar a elaboração de um plano de regulamentação dos usos e atividades permitidas na orla visando ainda fomentar o desenvolvimento socioeconômico aliado à preservação ambiental.

A partir disso, foram realizas oficinas locais com três grupos de trabalho com o propósito de levantar e discutir soluções sobre a orla: o Grupo I reuniu representantes da Associação de Moradores do Xexé, Projeto TAMAR, UFRRJ/Campos, Guarda Civil Municipal, Secretaria Municipal de Agricultura e Pesca; o Grupo II reuniu representantes da AMAFROL, quiosqueiros, barqueiros e trabalhadores da pesca, Colônia de Pescadores, Guarda Civil Municipal e Superintendência de Postura Municipal; e o Grupo III reuniu representantes da Secretaria Municipal de Desenvolvimento Econômico e Petróleo (SEDEP), Defesa Civil Municipal, Companhia de Desenvolvimento do Município de Campos (CODEMCA), AMAFROL, Guarda Civil Municipal, UFRRJ/Campos, INEA e a ASHCOM. Todos os três grupos tiveram três reuniões cada, realizadas entre os meses de agosto e novembro de 2010. Essas oficinas locais buscaram objetivamente cooperar na elaboração do Plano de Gestão Integrada (PGI) do Projeto Orla, mais especificamente na elaboração de um diagnóstico detalhado e na construção dos quadros de ações e cenários desejados para a orla do município.

A tipologia (atributos físicos e forma de ocupação) e classificação de cada trecho de orla seguiram a seguinte denotação: Classe $\mathrm{A}$ - orla com baixíssima ocupação e paisagens com alto grau de originalidade; Classe B - baixo a médio adensamento de construções e população residente e paisagem parcialmente antropizadas e; Classe $\mathrm{C}$ - médio a alto adensamento de construções e populações residentes com paisagens antropizadas, multiplicidade de usos e alto potencial de poluição.

A $2^{\mathrm{a}}$ Oficina do Projeto Orla (janeiro de 2011) consolidou os quadros de ações e medidas estratégicas para a orla do município. Nesta oficina foi formado o Pré-Comitê Gestor do Projeto Orla sendo o grupo paritário entre órgãos municipais e a sociedade civil organizada. A composição do pré-comitê gestor reúne as secretarias municipais de: Meio Ambiente; Obras e Urbanismo; Agricultura e Pesca; Desenvolvimento Econômico e Petróleo. Além dos órgãos Postura
Municipal; Guarda Civil Municipal; e CIDAC. Já a sociedade civil está representada pela Colônia de Pescadores; Associação de Moradores do Xexé; AMAFROL; ASHCOM; Projeto Tamar; UFF/Campos e UFRRJ/Campos. O Pré-Comitê Gestor reuniu-se 12 vezes desde janeiro de 2011 até agosto de 2012 para discutir e tomar providências em relação às questões de ordenamento, adequações, intervenções durante o verão, preparação de material, produção de quadros e configuração da orla e demais discussões relacionadas ao PGI. Paralelamente foram realizadas pesquisas documentais e na literatura científica, levantamentos de campo e mapeamentos para compor os resultados apresentados no PGI e neste artigo.

\section{RESULTADOS}

As oficinas realizadas e o trabalho posterior do Pré-Comitê Gestor geraram um diagnóstico detalhado que partiu da compartimentação da orla em três unidades de paisagem e subdivisão das mesmas em quatorze trechos, a serem descritos a seguir.

Compartimentação, Descrição e Medidas a serem adotadas na Orla do Município. Unidade I - Da Divisa da Barra do Açu à Vila do Sol.

Estende-se por 15,4 km desde o limite norte da orla do município de Campos dos Goytacazes (RJ) com o município de São João da Barra (RJ) até a localidade conhecida como Vila do Sol, ao sul (Figura 2). 
Projeto de gestão integrada da orla marítima. A experiência do município de Campos dos Goytacazes, Rio de Janeiro, Brasil. Eduardo Manuel Rosa Bulhoes, Stéphanie Katrin Vianna Klotz, Izaura da Silva Arêas Mota, Tatiane Cardoso Tavares, Juliana Bastos

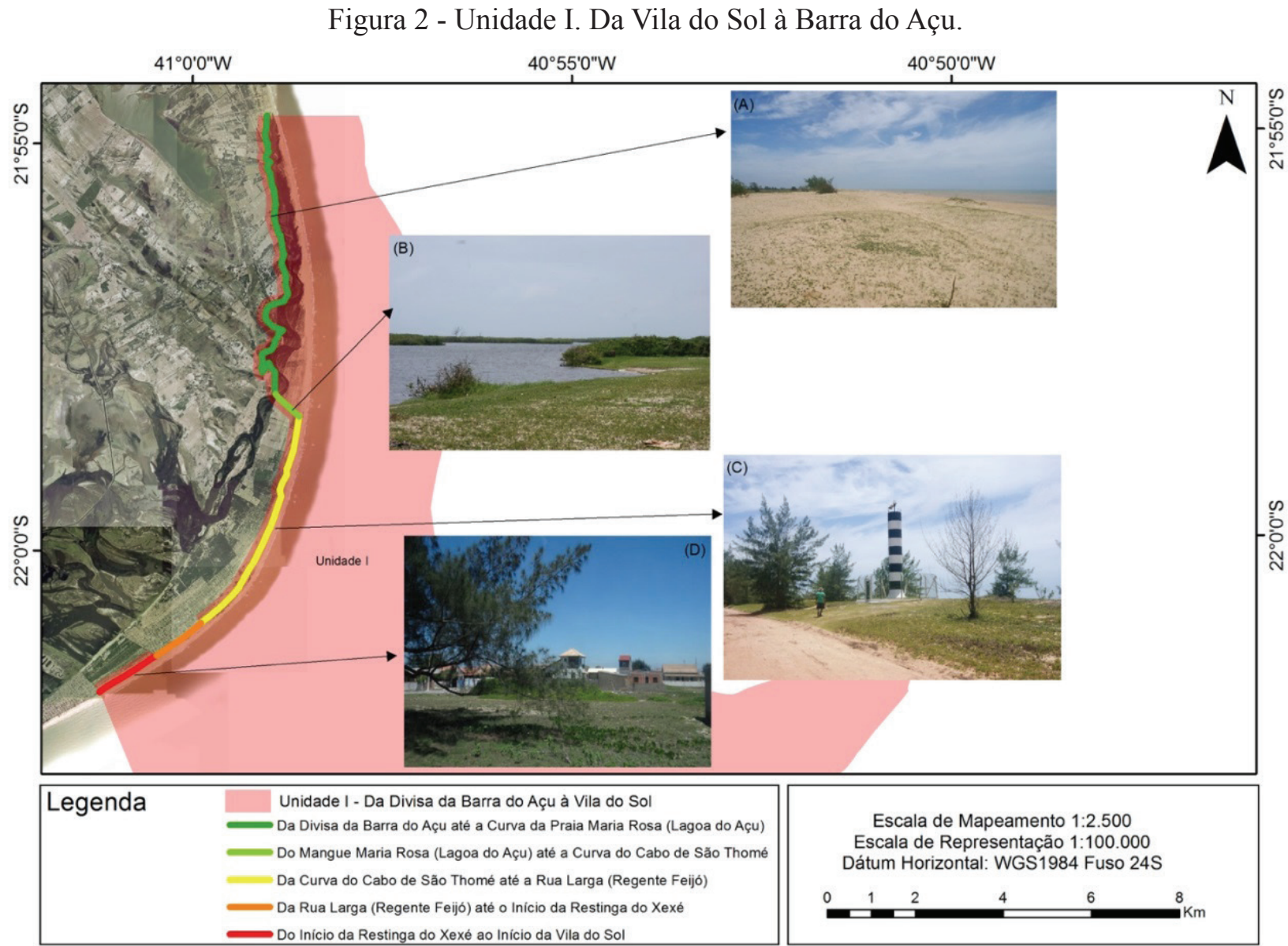

Mapa e Fotos A e C: Autores.

Fotos B e D: PGI (2015).

Trata-se de uma extensa área de restinga onde existe o contato da Lagoa Salgada com o mar. O contato se dá permanentemente via água subterrânea e episodicamente via abertura da barra da laguna por ação de transposição de ondas ou em períodos de cheia pluviométrica. Esse contato permite a existência de vegetação de mangue bem desenvolvida e preservada ao longo das margens da laguna. A demanda de proteção ambiental desta área, aspirada pela comunidade e pelo Pré Comitê Gestor, foi atendida pela criação da UC Parque Estadual da Lagoa do Açu (PELAG), através do Decreto Estadual $\mathrm{n}^{\mathrm{o}} 43.522$, de $20 / 03 / 2012$. Esta unidade foi subdividida em 5 trechos que serão descritos a seguir.

\section{Unidade I, Trecho 01 - Da Divisa da Barra do Açu até a curva da praia Maria Rosa (Lagoa do Açu).}

Estende-se por 7,9 km e foi diagnosticado como classe "A" do tipo orla exposta, sem ocupação, com ambiente bem preservado (Figura 02, foto A) além de ser área de desova de tartarugas marinhas in situ. Definiu-se como trecho potencial para a elaboração de estudos ambientais e criação de UC de Proteção Integral. Há problemas como a presença de animais de pastoreio e descarte de ossadas, ocasionando a dispersão de odores e degradação do solo, resultante de atividades comerciais. Em relação ao cenário de usos desejados, observou-se que a área se encontra loteada com tendência para o surgimento de construções desordenadas e aumento da área de pasto com supressão de elementos da fauna e da flora nativa, ocasionando perda na qualidade da paisagem. O cenário desejado, seria garantir a preservação de toda área de restinga e mangue.

\section{Unidade I - Trecho 02 - Do Mangue Maria Rosa (Lagoa do Açu) até a curva do Cabo de São Thomé.}

Estende por $740 \mathrm{~m}$ e foi diagnosticado como classe "A". Constatou-se atividades de recreação e pesca artesanal. A paisagem é de diversidade ambien- 
Projeto de gestão integrada da orla marítima. A experiência do município de Campos dos Goytacazes, Rio de Janeiro, Brasil. Eduardo Manuel Rosa Bulhoes, Stéphanie Katrin Vianna Klotz, Izaura da Silva Arêas Mota, Tatiane Cardoso Tavares, Juliana Bastos Sanguêdo, Carolina Almeida Santos Cidade

tal e valor cênico (Figura 2, foto B) com potencial para o turismo. Problemas estão relacionados ao turismo e ao comércio, identificados pela existência de barracas comerciais irregulares e falta de saneamento, causando problemas como disposição e descarte inadequado de resíduos sólidos e efluentes sanitários, além de desmatamento de áreas marginais. Inferiu-se a tendência de supressão da vegetação, aumento do descarte irregular de resíduos, aumento das áreas de pastagem, redução do pescado, construção de quiosques de alvenaria, ocasionando potencialmente maior poluição e assoreamento da Lagoa do Açu. Em relação ao cenário de usos desejados, identificou-se a necessidade de viabilizar a recuperação da vegetação do mangue, a redução ou eliminação da área de pastagem, controle e restrição de uso da área de forma a evitar o despejo irregular de resíduos, preservar e garantir o potencial para pesca artesanal, criar uma área limitada destinada a alimentação, sendo realizado pelo comércio ambulante, com os seguintes suportes: banheiro químico, guarda-vidas, ambulância e policiamento, além da construção de calçadão, ciclovia e iluminação adequada que viabilize segurança aos moradores e visitantes sem comprometer a desova das tartarugas marinhas.

\section{Unidade I, Trecho 03 - Da curva do Cabo de São Thomé até a Rua Larga (Regente Feijó).}

Estende por 5,4 km e foi diagnosticado como classe "B" do tipo orla exposta com urbanização em processo de consolidação horizontal, além de ser uma área de desova de tartarugas marinhas in situ. Constatou-se o potencial para instalação de estruturas turístico-ecológicas. Problemas citados foram: expansão imobiliária desordenada, fluxo turístico concentrado em curto período do ano (verão), inexistência de infraestrutura e serviços de apoio, realização de eventos em área de preservação permanente, trânsito de veículos na faixa de areia, além da invasão de espécies exóticas (casuarinas) em área de preservação causando descaracterização da paisagem. As atividades geradoras destes impactos são turismo, comércio e veraneio. Em relação ao cenário de usos desejados para a orla foi indicado viabilizar a construção ordenada de residências e comércio, além da expansão do saneamento básico, controle do crescimento das casuarinas, construção limitada de quiosques e posto de observação de guarda-vidas, pavimentação da estrada e das ruas, construção de calçadão e ciclovia e provimento de iluminação adequada que possibilite segurança aos moradores e visitantes sem comprometer a desova das tartarugas marinhas.

\section{Unidade I, Trecho 04 - Da Rua Larga (Regente Feijó) até o início da Restinga Xexé.}

Estende-se por 1,2 km e foi diagnosticado como classe "B" do tipo orla exposta com urbanização em vias de consolidação. Quanto aos problemas, suas atividades geradoras, seus efeitos e impactos associados, os mesmos são idênticos ao trecho 03 supracitado. Em relação ao cenário de usos desejados para a orla, foram apontados: necessidade de controle das construções residenciais e comerciais, saneamento, acessibilidade ao mar, postos de observação de guarda vidas, provimentos de serviços de saúde e segurança pública, além da construção de calçadão, ciclovia e iluminação pública adequada.

\section{Unidade I, Trecho 05-Do início da Restinga do Xexé ao início da Regente Feijó).}

Estende por 5,4 km e foi diagnosticado como classe "B" do tipo orla exposta com urbanização em processo de consolidação horizontal, além de ser uma área de desova para espécies ameaçadas, além de ser uma área de desova de tartarugas marinhas in situ, sem interferência. Constatou-se que este trecho possui potencial para inclusão em uma UC, além de possibilitar o manejo e extração de produtos naturais, propiciando pesquisa científica, além da criação de projetos de educação ambiental para a comunidade. Problemas apontados foram: descarte de resíduos orgânicos e inorgânicos (principalmente de pescado), presença de animais de pastoreio, a ausência de iluminação, veículos na faixa de areia, além de extração irregular de areia da praia, causando redução da qualidade da paisagem e degradação ambiental. Problemas apontados como resultantes das atividades de pesca e construção civil. Em relação ao cenário de usos desejados foram apontados a criação de área para preservação da desova das tartarugas marinhas, além de passarela de acesso ao mar, com ciclovia/ciclo faixa para caminhada e ciclismo, da criação de uma área destinada para passeios, trilhas e estudos ecológicos com estrutura 
Projeto de gestão integrada da orla marítima. A experiência do município de Campos dos Goytacazes, Rio de Janeiro, Brasil.

Eduardo Manuel Rosa Bulhoes, Stéphanie Katrin Vianna Klotz, Izaura da Silva Arêas Mota, Tatiane Cardoso Tavares, Juliana Bastos

Sanguêdo, Carolina Almeida Santos Cidade

adequada e criação de uma unidade do Projeto TAMAR.

Para finalizar o diagnóstico da Unidade I, foram indicadas como ações e medidas estratégicas a regulação de uso e a criação de UC (demanda atendida), a elaboração da pavimentação no modelo estrada-parque, a restrição à construção de quiosques, elaboração de um plano de saneamento, construção de calçadão e ciclovia para garantir acessibilidade, iluminação pública adequada, criação de UC em área contemplativa do remanescente de restinga (restinga do Xexé) e instalação de uma base do TAMAR, com as finalidades de garantir a preservação ambiental, a proteção da área de desova das tartarugas e a criação de áreas públicas de lazer ecológico. Essas ações e medidas teriam a duração que variariam desde seu início imediato até 5 anos. Os órgãos responsáveis seriam: INEA, Programa Nacional de Desenvolvimento do Turismo
(PRODETUR), a Prefeitura Municipal de Campos dos Goytacazes (PMCG) através das secretarias de meio ambiente, obras e da Empresa Municipal de Habitação, Urbanização e Saneamento (EHMAB), a SEA - Secretaria Estadual do Ambiente e o Governo Federal (CAIXA) e as PPP (Parcerias Público Privadas).

\section{UNIDADE II - Da Vila do Sol ao Camping.}

Estende-se por aproximados 6,2 km entre a localidade Vila do Sol e o Camping (Figura 3). É a área urbanizada da orla costeira do município de Campos dos Goytacazes e engloba os principais núcleos urbanos, sendo estes o Farol de São Thomé e Xexé. As características da praia arenosa remontam às praias urbanizadas onde a extensão da faixa de areia é interrompida pelo calçadão da orla.

Figura 3 - Unidade II - Da Vila do Sol ao Camping.

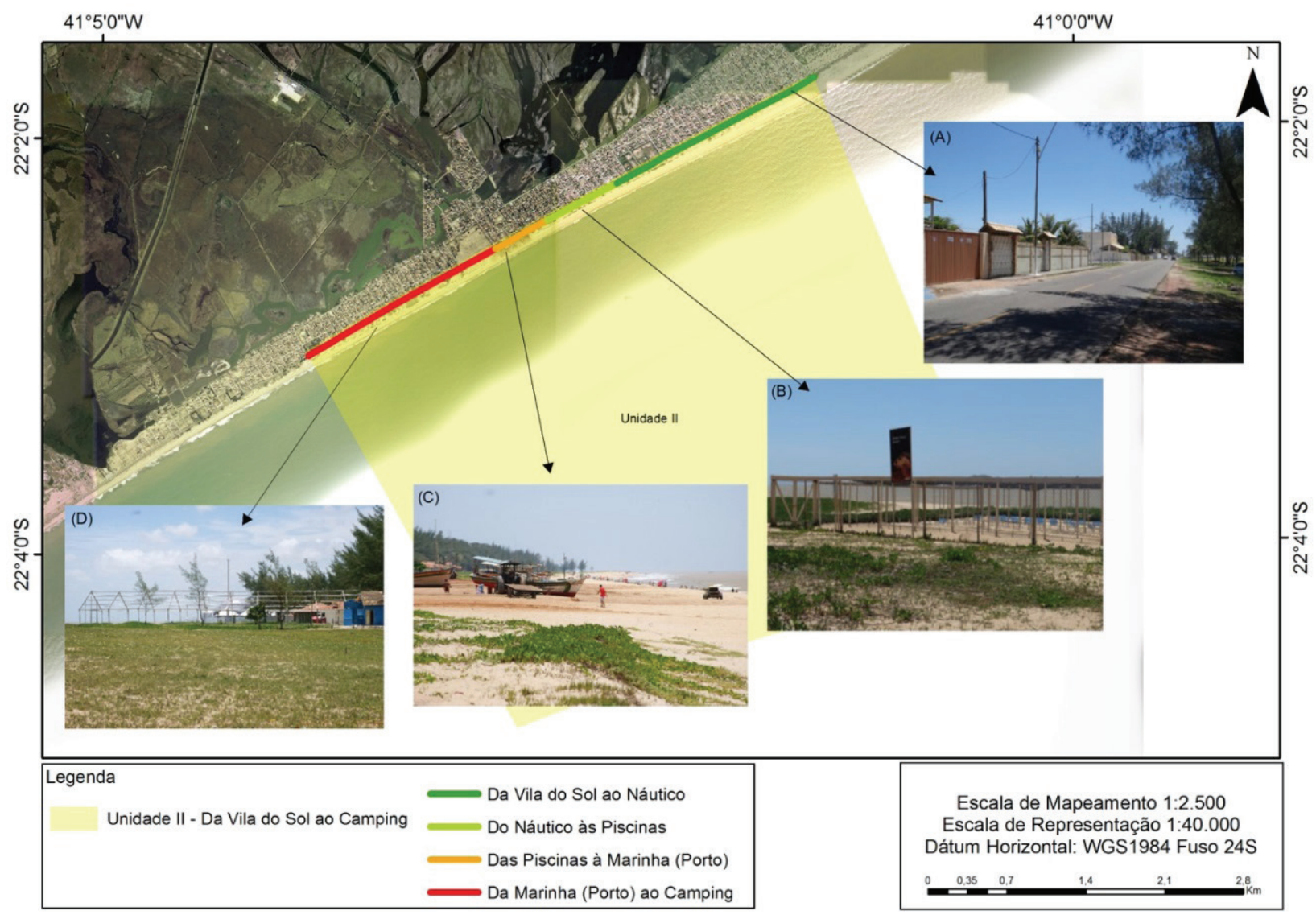

Mapa e Fotos C e D: Autores

Fotos A e B: PGI (2015) 
Projeto de gestão integrada da orla marítima. A experiência do município de Campos dos Goytacazes, Rio de Janeiro, Brasil. Eduardo Manuel Rosa Bulhoes, Stéphanie Katrin Vianna Klotz, Izaura da Silva Arêas Mota, Tatiane Cardoso Tavares, Juliana Bastos Sanguêdo, Carolina Almeida Santos Cidade

Há presença de vegetação de restinga e pequenas dunas frontais, além de duas bermas elevadas. Morfologicamente é uma área aonde há o predomínio de transporte de sedimentos, na maior parte do ano para o Sul e é também sujeita a eventos episódicos de ondas de tempestade (de sul e sudeste) que invertem o sentido do transporte litorâneo e podem transpor os limites da praia. Esta unidade foi subdividida em 4 trechos a serem descritos a seguir:

\section{Unidade II, Trecho 01- Da Vila do Sol ao Náutico.}

Estende-se por 2,0 km e foi diagnosticado como classe "B" do tipo orla exposta com urbanização em processo de expansão, com construções horizontais e algumas áreas de praia ainda bem preservadas. Constatou-se tendência de verticalização das construções. Quanto aos problemas, foram identificados: resíduos urbanos em geral, descartes de sucatas, extração irregular de areia e presença de animais e excrementos na faixa arenosa, causando poluição ambiental. Em relação ao cenário de usos desejados para a orla seria viabilizar a construção de ciclovia e calçadão, de possibilitar uma melhor acessibilidade ao mar, de melhorias na rede de saneamento básico, além da reestruturação do bosque das áreas verdes.

\section{Unidade II, Trecho 02 - Do Náutico às Piscinas.}

Estende-se por 700 metros e foi diagnosticado como classe "B", do tipo orla exposta com urbanização em processo de consolidação. Constatou-se potencial para atividades de recreação e lazer, bem como para as atividades do Projeto TAMAR. Problemas diversos foram apontados, como: utilização da faixa de areia com bancos fixos nos quiosques, presença de sanitários, fossas, palco, chuveiros, praças, postes de iluminação pública e toldos, trânsito de veículos na faixa de areias e animais soltos. As consequências são poluição do lençol freático e agressão à composição botânica natural da faixa arenosa e revolvimento da areia. Sendo isso, resultado do turismo e comércio. Em relação ao cenário de usos desejados para a orla seriam: a recomposição da vegetação fixadora de areia, mudança dos quiosques do primeiro para o segundo calçadão (padronização), ampliação do calçadão, construção de ciclovia e ampliação da área de lazer, além de melhorar a estrutura de saneamento.

\section{Unidade II, Trecho 03 - Das Piscinas à Marinha (Porto).}

Estende-se por $520 \mathrm{~m}$ e foi diagnosticado como classe "B" do tipo orla exposta com urbanização consolidada em processo de verticalização, além da utilização da faixa de areia como espaço comercial privado com edificações para limpeza e comercialização de pescados, estaleiros para reforma e construção de barcos a céu aberto, depósito de gelo e outros, pátio para caminhões que transitam sobre a areia para o transporte de pescados, tratores para arrasto das embarcações (Figura 02, foto C), equipamentos institucionais, piscinas infantis, campos de futebol, postes de iluminação pública, tendas e quiosques. Constatou-se também que este trecho possui potencial para atividades de lazer e turísticas, como a prática de esportes náuticos. Devido as suas condições naturais, essa área torna-se propícia para manutenção de porto de saída e chegada das embarcações pesqueiras, até que se encontre uma melhor solução. Os problemas como poluição e consequentemente degradação ambiental são em maior parte ocasionados pelo uso indevido da faixa de areia tais como citados acima sendo estas resultantes das atividades de pesca, turismo e comércio. Em relação ao cenário de usos desejados para a orla, indicou-se a implementação e ordenamento do porto com delimitação da área restrita para as embarcações pesqueiras até que haja solução técnica adequada, da construção de um entreposto pesqueiro com toda estrutura adequada para o desenvolvimento da pesca artesanal, construção de quiosques padronizados sobre o $2^{\circ}$ calçadão (mais afastado da areia) e área de lazer, da definição de área adequada para peixarias, feira da roça e outros, da recuperação da área de cobertura vegetal, saneamento básico, melhor acessibilidade ao mar, maior atuação da SMMA, Postura e Defesa Civil, além da construção de calçadão e ciclovia. 
Projeto de gestão integrada da orla marítima. A experiência do município de Campos dos Goytacazes, Rio de Janeiro, Brasil.

Eduardo Manuel Rosa Bulhoes, Stéphanie Katrin Vianna Klotz, Izaura da Silva Arêas Mota, Tatiane Cardoso Tavares, Juliana Bastos

Sanguêdo, Carolina Almeida Santos Cidade

Unidade II, Trecho 04 - Da Marinha (Porto) ao Camping.

Estende-se por $1,9 \mathrm{~km}$ e foi diagnosticado como classe "B" do tipo orla exposta com urbanização horizontal em processo de expansão, além da utilização da faixa de areia com ocupações de unidades municipais, quiosques e guarda sol de alvenaria para uso público. Constatou-se potencial para atividades turísticas e de lazer, além da prática de esportes náuticos. Diversos problemas foram apontados, como: presença de animais na faixa arenosa, fossas inadequadas nos quiosques, resíduos diversos e postes de iluminação pública fixos na faixa de areia, causando a poluição do lençol freático, agressão à composição botânica natural da faixa arenosa e a perda da qualidade ambiental, resultantes do turismo e comércio. Em relação ao cenário de usos desejados para a orla seria poder tonar viável a implementação do afastamento dos quiosques para o $2^{\circ}$ calçadão, saneamento básico, área de lazer, construção de ciclovia e calçadão, estrutura delimitada para realização de eventos, construção de quiosques padronizados em toda a orla em número e distância previamente definidos e de melhorara a acessibilidade ao mar.

Para finalizar o diagnóstico da Unidade II foram pensadas como ações e medidas estratégicas, a elaboração de um Plano de Expansão do Saneamento do Farol com ênfase no saneamento ambiental, no escoamento das águas pluviais e no tratamento de esgoto, além de formular um projeto de infraestrutura e urbanismo. Outras demandas são: melhorar a acessibilidade ao mar, construção de calçadão e ciclovia, regularização do uso e ocupação dos espaços públicos da União pelos quiosques e pelas estruturas municipais, retirar construções na faixa de areia, promover o ordenamento da área ocupada pelo porto pesqueiro e adequação da iluminação em toda à orla. A finalidade é garantir às condições efetivas de acesso à qualidade de vida, garantir a saúde da população, conquistar obediência em relação à legislação patrimonial e ao projeto urbanístico municipal, promover maior segurança, preservar a desova das tartarugas marinhas e desenvolver a pesca artesanal. Essas ações e medidas teriam a duração de que variam desde seu início imediato até 5 anos. Os órgãos responsáveis por essas ações seriam a PMCG, a iniciativa privada, o INEA, o SPU e o Comitê Gestor.

\section{UNIDADE III - Do Camping à divisa da Barra do Furado.}

Estende-se por 7,1 km do Camping à divisa da Barra do Furado e marca o contato, ao sul, da orla do município de Campos dos Goytacazes com o canal das Flechas, limítrofe ao município de Quissamã (RJ) (Figura 4, foto E) na localidade de Barra do Furado. 
Projeto de gestão integrada da orla marítima. A experiência do município de Campos dos Goytacazes, Rio de Janeiro, Brasil. Eduardo Manuel Rosa Bulhoes, Stéphanie Katrin Vianna Klotz, Izaura da Silva Arêas Mota, Tatiane Cardoso Tavares, Juliana Bastos Sanguêdo, Carolina Almeida Santos Cidade

Figura 4 - Unidade III - Do Camping ao Canal das Flechas.

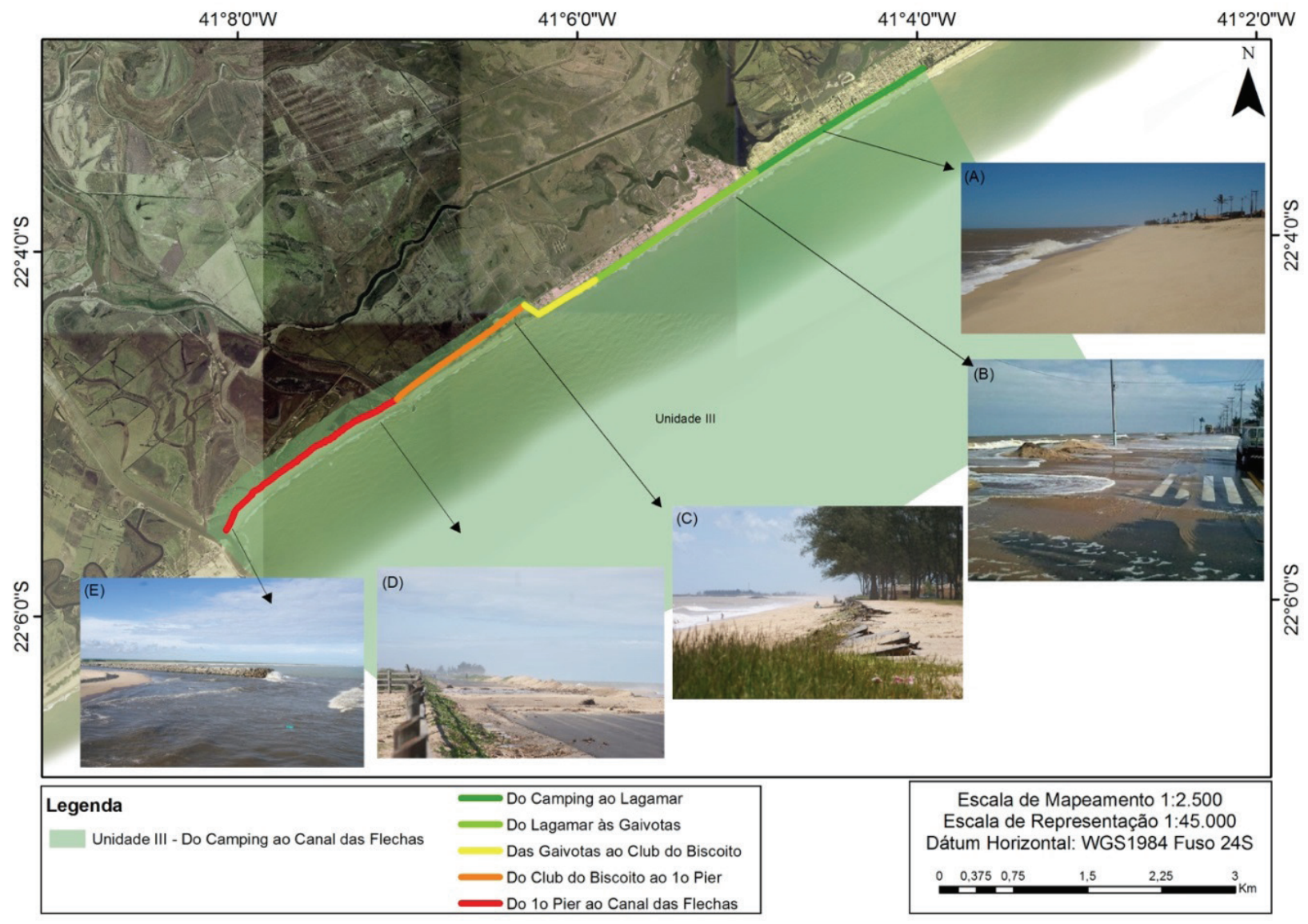

Mapa e Fotos A, C, D e E: Autores. Foto B: O Diário de Campos.

Ao sul desta unidade ocorre uma área de mangue conhecida como Mangue da Carapeba. Desde que um guia corrente foi instalado para a fixação das margens na foz do Canal das Flechas existe uma tendência de recuo da linha de costa através de processos de impedimento da chegada de sedimentos vindos de sul, portanto, o ajuste erosivo se dá por transposição de ondas (figura 4, foto D) e pelo recuo da linha de costa ao longo de toda esta unidade.

\section{Unidade III, Trecho 01- Do Camping ao Lagamar.}

Estende-se por $2 \mathrm{~km}$ e foi diagnosticado como classe "B" do tipo orla exposta urbanizada. Constatou-se potencial turístico em função da paisagem e da balneabilidade. Problemas como utilização da faixa de areia como raia de hipismo, quiosques, trailers, campos para prática de esportes, além da existência de vegetação exótica, erosão da praia e descarte irregular de resíduos foram identificados como potenciais redutores da qualidade da paisagem. A poluição ambiental ocorre sobretudo pela disposição inadequada de resíduos sólidos e efluentes sanitários resultantes das atividades de turismo, comércio e construção civil. Em relação ao cenário de usos desejados foi indicado viabilizar a retirada das estruturas de alvenaria, campo de futebol e trailers sobre a faixa de areia. Melhorar a acessibilidade ao mar, recuperar a vegetação de restinga, replantio de árvores no entorno do Lagamar, construção de uma estação de tratamento de efluentes (ETE), realocar a raia (corrida de cavalos), reconstruir o calçadão e implementar ciclovia. 
Projeto de gestão integrada da orla marítima. A experiência do município de Campos dos Goytacazes, Rio de Janeiro, Brasil.

Eduardo Manuel Rosa Bulhoes, Stéphanie Katrin Vianna Klotz, Izaura da Silva Arêas Mota, Tatiane Cardoso Tavares, Juliana Bastos

Sanguêdo, Carolina Almeida Santos Cidade

Unidade III, Trecho 02 - Do Lagamar às Gaivotas.

Estende-se por $1,95 \mathrm{~km}$ e foi diagnosticado como classe "B" do tipo orla exposta em processo de urbanização. Constatou-se elevado potencial paisagístico, contendo vegetação de restinga, lagoa costeira e praia. Inclui a APA (Área de Proteção Ambiental) do Lagamar criada em 1993 e que mantém aspectos positivos no que concerne à balneabilidade. Os problemas de uso identificados foram: erosão costeira, alagamento por ondas de tempestade (Figura 4, foto B), vegetação exótica (casuarinas) e descarte irregular de resíduos. Há construções irregulares despejando esgoto direto na lagoa costeira e postes de iluminação pública na faixa de areia. Desta forma, há prejuízos à qualidade da paisagem, além de poluição e degradação ambiental causada também pela disposição inadequada de resíduos sólidos e efluentes sanitários, resultantes do comércio e da construção civil. Em relação ao cenário de usos desejados para a orla, seria mitigar o processo erosivo, recuperar a restinga, repavimentar a estrada, construir calçadão e ciclovia.

\section{Unidade III, Trecho 03 - Das Gaivotas ao Club do Biscoito.}

Estende-se por $840 \mathrm{~m}$ e foi diagnosticado como classe "A" do tipo orla exposta com urbanização rarefeita. Constatou-se que o trecho possui potencial paisagistico em função das áreas de restinga e mangue. Problemas de uso são: contaminação do lençol freático, vegetação exótica, erosão da praia (Figura 4 , foto C), descarte irregular de resíduos, perturbação do mangue, além da construção de estrada. Desta forma, estes problemas causam a redução da qualidade ambiental e descaracterização da paisagem. Sendo isso, resultante do comércio e da construção civil. Em relação ao cenário de usos desejados para a orla, observou-se a tendência de erosão continuada da praia e avanço do mar com destruição da estrada, loteamentos, casas e árvores, extinção de faixa de areia e da restinga. $\mathrm{O}$ cenário desejado, é idêntico ao trecho 02 desta unidade.

Unidade III, Trecho 04 - Do Club do Biscoito ao $1^{\circ}$ Píer
Estende-se por $1,6 \mathrm{~km}$ e foi diagnosticado como classe "A" do tipo orla exposta pouco urbanizada. Constatou-se potencial paisagístico devido à praia selvagem com vegetação de pouco alterada. Os problemas são a existência de pastagem, construção de estrada e erosão da praia (Figura 4, foto D), perturbação do mangue, descarte irregular de resíduos de pesca e domésticos e presença de vegetação exótica, causando redução da qualidade ambiental, descaracterização da paisagem, sendo estes resultantes de atividades como a pecuária e o comércio. Em relação ao cenário de usos desejados para a orla, observou-se que a tendência é que haja acentuação da erosão da praia e pelo avanço do mar a salinização das terras. Destruição da estrada e loteamentos. Extinção da restinga. O cenário desejado é a recuperação de restinga, repavimentação da estrada, fiscalização permanente e construção de calçadão e ciclovia.

\section{Unidade III, Trecho 05 - Do $1^{\circ}$ Píer ao Canal das Flechas.}

Estende-se por 2,25 km até o final da orla do município (Figura 4, foto E). Foi diagnosticado como classe " $\mathrm{A}$ " do tipo orla exposta não urbanizada. Constatou-se que este trecho possui potencial paisagístico devido à diversidade ambiental, visto que, além da praia ser selvagem com vegetação nativa preservada, existe uma vasta área de mangue à retaguarda. Há previsão de criação de uma UC pelo plano diretor do município. Os problemas identificados são: erosão da praia, circulação de água contaminada no mangue, presença de vegetação exótica e pasto. Além disso, descarte irregular de resíduos de pescado, construções abandonadas, trânsito de veículos na faixa arenosa, dentre outros. Desta forma, há redução da qualidade ambiental, descaracterização da paisagem e comprometimento do lençol freático, sendo estas consequências das atividades de pecuária e pesca. Em relação ao cenário desejado foi citada a abertura permanente do canal e retirada do píer (enrocamento com pedras) se necessário, recuperação da restinga, delimitação de área de pastagem e fiscalização permanente, construção de calçadão e ciclovia e criação de UC no Mangue da Carapeba.

Para finalizar o diagnóstico da Unidade III 
Projeto de gestão integrada da orla marítima. A experiência do município de Campos dos Goytacazes, Rio de Janeiro, Brasil. Eduardo Manuel Rosa Bulhoes, Stéphanie Katrin Vianna Klotz, Izaura da Silva Arêas Mota, Tatiane Cardoso Tavares, Juliana Bastos Sanguêdo, Carolina Almeida Santos Cidade

como um todo, foram pensadas como ações e medidas estratégicas: a elaboração de um estudo técnico do estuário do Canal das Flechas e de monitoramento da erosão costeira; criação de UC no Mangue da Carapeba; restrição às ocupações na faixa de 200m; criação do conselho consultivo da APA do Lagamar; Plano de Expansão do Saneamento do Farol; realocar a raia de cavalos; restaurar a vegetação psamófila; retirar o comércio existente na faixa de areia; elaborar a construção de calçadão, ciclovia / ciclo faixa; e melhorar a acessibilidade ao mar. As finalidades são: preservar a área, evitar construções irregulares, contribuir para a mitigação da erosão costeira, propiciar qualidade de vida à população local e aos turistas, manter a tradição local, equilibrar o ecossistema, promover a obediência à legislação pertinente. Os órgãos responsáveis por essas ações seriam o PMCG ou particular, o SPU, o INEA e o Comitê Gestor.

\section{SÍNTESE DOS RESULTADOS E DISCUSSÃO}

O município de Campos dos Goytacazes possui 28 quilômetros de orla marítima, exposta, com trechos nativos, urbanizados e em processo de urbanização. O relevo é de planície, formado por terrenos baixos arenosos aonde ocorrem restingas, áreas de mangue, áreas periodicamente alagadas, lagoas e rios. As áreas já sujeitas à regulamentação são as UCs que tem seus limites dentro da orla do município como o PELAG e a APA Lagamar. Os conflitos ambientais pelo uso das áreas naturais fora dos limites das UCs esbarram nas atividades já consolidadas e identificadas como geradoras de problemas e essas foram atribuídas ao comércio, à pesca, ao turismo e veraneio e à construção civil.

Um zoneamento ecológico da zona costeira do município foi proposto visando ordenar às atividades que demandam regularmente a utilização da faixa de areia, de mar e/ou as áreas inseridas nos limites do projeto orla municipal, e este zoneamento visou delimitar as áreas preferenciais para atividades como banho de mar, práticas desportivas, entrada e saída de embarcações pesqueiras dentre outras.

Oliveira e Nicolodi (2012) ao realizarem uma análise no âmbito nacional sobre os 10 anos do Projeto Orla no Brasil, destacam a inserção do município de
Campos dos Goytacazes no contexto das atividades de extração de óleo e gás na plataforma continental da Bacia de Campos, justificando a preocupação do Governo Federal em situar este município e outros do Norte Fluminense na $1^{\mathrm{a}}$ fase (2001-2004) da implementação e consolidação desta política de gestão da zona costeira. No entanto, segundo os autores, a falta de recursos humanos e financeiros nos municípios foram as principais dificuldades enfrentadas para a implementação dos PGIs em todo o país. Os avanços em comum foram a incorporação de ações definidas em PGIs em práticas ambientais do estado, como por exemplo, a incorporação de áreas de orla em UCs. O exemplo do PELAG, criado em 2012, com a incorporação de parte da porção norte do município de Campos dos Goytacazes como área de proteção integral é um exemplo deste avanço.

Voivodic (2007), ao analisar o Projeto Orla no município de Cabo Frio, faz uma crítica em relação a não incorporação dos PGIs e dos seus avanços, como o diagnóstico e a definição de usos e atividades na orla marítima, aos Planos Diretores municipais dos municípios fluminenses como Campos dos Goytacazes. Em 2013, a PMGC aprovou a Lei 8.335/2013 que institui o Plano Municipal de Gerenciamento Costeiro (regulamentada pelo Decreto Municipal no. 179 de 22/07/2015) que, apesar de não ser propriamente a efetivação política de um planejamento urbano consoante com as diretrizes do Projeto Orla, prevê a execução do Zoneamento Ecológico-Econômico Costeiro que definirá normas e metas no âmbito ambiental, rural e urbano, o que de fato representa um avanço na legislação municipal face ao planejamento da orla do município, e sem dúvida um dos legados da discussão em torno do Projeto Orla.

\section{Avanços no Processo e Momento Atual}

$\mathrm{Na}$ forma como foi consolidado utilizando as informações apresentadas no diagnóstico e nos cenários desejados para orla o PGI foi submetido à avaliação da instrutora do Projeto Orla que emitiu parecer, em março de 2014, atestando à adequação do mesmo à metodologia especifica determinada pelos manuais do Projeto Orla. 
Projeto de gestão integrada da orla marítima. A experiência do município de Campos dos Goytacazes, Rio de Janeiro, Brasil.

Eduardo Manuel Rosa Bulhoes, Stéphanie Katrin Vianna Klotz, Izaura da Silva Arêas Mota, Tatiane Cardoso Tavares, Juliana Bastos

Sanguêdo, Carolina Almeida Santos Cidade

Em seguida o PGI foi encaminhado para a análise das coordenações técnica nacional (SPU/RJ; Departamento de Zoneamento Territorial/MMA); e estadual que, após um período de avaliação e posicionamentos institucionais (SEPLAG - Secretaria Estadual de Planejamento; SEDRAP/FIPERJ - Secretaria Estadual de Desenvolvimento Regional, Abastecimento e Pesca; INEPAC - Instituto Estadual do Patrimônio Cultural; IPHAN - Instituto do Patrimônio Histórico Artístico Nacional) emitiu parecer com suas considerações e recomendações técnicas (forma e conteúdo) e sugestões de adequação, em dezembro de 2014. Por fim, foram feitas as adequações sugeridas e o PGI, assim como o Comitê Gestor, foram aprovados e homologados em Audiência Pública no dia 16 de maio de 2015. O destaque para este fato é que o PGI de Campos dos Goytacazes é o primeiro a ser homologado no estado do Rio de Janeiro.

O Plano de Gestão Integrada aprovado estabelece metas a serem cumpridas em até 5 anos, de acordo com cronograma estabelecido. Estas metas são chamadas de Plano de Ações e funcionam como um direcionamento do que deve ser realizado ao longo da implantação do Projeto Orla. As atividades que antecederam a aprovação este projeto, foram de fato uma preparação para a formulação do PGI. O Plano de Ações é subdividido dentro das três unidades que compreendem a orla municipal, devido às diferentes demandas de cada uma delas. O PGI não é imutável, como este é um plano em processo de implementação o mesmo se encontra em constante análise e discussão pela SMMA em conjunto com o Comitê Gestor.

$\mathrm{O}$ cronograma geral estabelece as atividades que devem ser realizadas e qual o prazo estimado que estas devem estar concluídas, dessa forma o PGI tem a função de guiar e auxiliar a execução de cada medida delineada para a orla do município.

Cabe também registrar que o momento atual é de prosseguimento das atividades através das reuniões iniciais e periódicas do Comitê Gestor (nomeado pela Portaria Municipal no. 29 de 15/06/2015) municipal que tem discutido pautas como regimento interno, formação de comissões técnicas, nomeação de conselheiros, dentre outros, e visam se consolidar como grupo representativo e atuante para o pleno desenvolvimento desta política pública na orla do município.

\section{CONCLUSÕES}

As etapas iniciais do Projeto Orla foram de fato consolidadas de forma participativa, com destaque para a fase de diagnóstico. Os resultados setorizados mostram o nível de maturidade da discussão e da percepção da comunidade (incluindo governo municipal e sociedade civil organizada) sobre os problemas da orla.

Ainda no diagnóstico, os problemas apontados, as tendências e os cenários desejados pelos munícipes demostram ampla preocupação com a qualidade ambiental e claro entendimento sobre quais atividades ameaçam esta e à qualidade de vida da comunidade. Neste sentido, demandas preservacionistas se misturam com demandas de infraestrutura e serviços urbanos, numa clara referência à manutenção e à ampliação da qualidade de vida local em que se conjuguem qualidade da paisagem, desenvolvimento e infraestrutura urbana.

Outro aspecto é que, apesar de $53 \%$ da orla ter sido diagnosticada como tipo "A" (alto grau de originalidade) é claro para os munícipes que, boa parte dessas áreas naturais, vem sendo degradada e pouco valorizada como elemento paisagístico de equilibrio ecológico, o que torna um litoral majoritariamente preservado alvo de pressões diversas e este aparentemente é o principal desafio ao desenvolvimento.

Por fim, a indicação das responsabilidades pelas ações e medidas estratégicas revela uma pletora de atores e instituições e os prazos apontados são curtos, o que aumenta a complexidade e o desafio das etapas seguintes do Projeto Orla no município, já em discussão por um Comitê Gestor consolidado e ativo.

\section{REFERÊNCIAS}

CASSAR, J.C.M.; NEVES, C.F. Aplicação das Rosas de Transporte Litorâneo à Costa Norte-Fluminense. Revista Brasileira de Engenharia, vol. 11, pp. 81106. 1993.

MMA - Ministério do Meio Ambiente, Ministério do Planejamento, Orçamento e Gestão. Projeto Orla: fundamentos para gestão integrada. Brasília. 74p. 2006a. Disponível em: <http://www.mma.gov.br/ estruturas/orla/_arquivos/11_04122008111238.pdf>. 
Projeto de gestão integrada da orla marítima. A experiência do município de Campos dos Goytacazes, Rio de Janeiro, Brasil. Eduardo Manuel Rosa Bulhoes, Stéphanie Katrin Vianna Klotz, Izaura da Silva Arêas Mota, Tatiane Cardoso Tavares, Juliana Bastos Sanguêdo, Carolina Almeida Santos Cidade

MMA - Ministério do Meio Ambiente, Ministério do Planejamento, Orçamento e Gestão. - Projeto Orla: manual de gestão. Brasília. 88p. 2006b. Disponível em: <http://www.mma.gov.br/estruturas/orla/_arquivos/11_04122008110636.pdf>.

MUEHE, D. O Litoral Brasileiro e sua Compartimentação. In: Guerra, A. J. T. \& Cunha, S.B. (org). Geomorfologia do Brasil. Cap. 7. Ed. Bertrand Brasil. 1998.

MUEHE, D. Erosão e Progradação no Litoral Brasileiro. MMA-Ministério do Meio Ambiente, Brasília. 2006.

OLIVEIRA, M.R.L.; NICOLODI, J.L. A Gestão Costeira no Brasil e os dez anos do Projeto Orla. Uma análise sob a ótica do poder público. Revista da Gestão Costeira Integrada, Vol. 12. pp. 91-100. 2004. DOI: 10.5894/rgci308

PGI - Projeto de Gestão Integrada da Orla Marítima de Campos dos Goytacazes. Plano de Intervenção na Orla do Município de Campos dos Goytacazes. 89 p. Disponibilidade Restrita. 2015.

PINHO, U. F. Caracterização dos Estados de Mar na Bacia de Campos. 2003. 123 f. Dissertação (Mestrado em Engenharia Oceânica) - COPPE/Universidade Federal do Rio de Janeiro, Rio de Janeiro. 2003.

VOIVODIC, R. Gestão Ambiental e Gerenciamento Costeiro Integrado no Brasil: uma análise do Projeto orla em Cabo Frio - RJ. 180 f. Dissertação (Mestrado em Geografia) PPGG/Universidade Federal do Rio de Janeiro, Rio de Janeiro. 2007. 